\title{
miRNAs involved in LY6K and estrogen receptor a contribute to tamoxifen-susceptibility in breast cancer
}

\author{
Ye Sol Kim ${ }^{1}$, Sae Jeong Park ${ }^{1}$, Yeon Seon Lee ${ }^{1}$, Hyun Kyung Kong ${ }^{1}$, Jong Hoon Park ${ }^{1}$ \\ ${ }^{1}$ Department of Biological Science, Sookmyung Women's University, Seoul, Korea \\ Correspondence to: Jong Hoon Park, email: parkjh@sookmyung.ac.kr \\ Hyun Kyung Kong, email: konghk@sookmyung.ac.kr
}

Keywords: breast cancer, tamoxifen susceptibility, LY6K, ERa, miRNA

Received: November 11, $2015 \quad$ Accepted: May 25, $2016 \quad$ Published: June 11, 2016

\section{ABSTRACT}

Estrogen receptor-alpha (ERa) is a clinically important therapeutic target for breast cancer. However, tumors that lose ERa are less responsive to anti-estrogens such as tamoxifen. MicroRNAs (miRNAs) are small RNAs that regulate expression of their target gene and dysregulations of miRNA has been identified in many diseases including human cancer. However, only a few miRNAs associated with tamoxifen resistance has been reported. In this study, we found that lymphocyte antigen 6

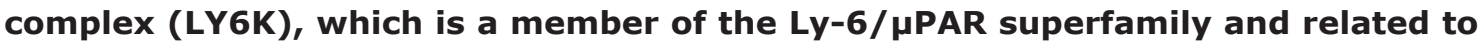
breast cancer progression and metastasis, is inversely correlated with ERa expression. We, for the first time, found miRNAs involved in the regulatory molecular mechanism between ERa and LY6K and related to tamoxifen susceptibility in breast cancer. miR-192-5p, induced by LY6K, downregulates ERa directly and induced tamoxifen resistance in ERa-positive breast cancer cells. In addition, re-expression of ERa in ERa-negative breast cancer cells increased miR-500a-3p expression and directly inhibits LY6K expression. Ectopic expression of miR-500a-3p sensitized ERa-negative cells to tamoxifen by increasing apoptosis. Finally, we observed an inverse correlation between LY6K and ERa in primary breast cancer samples. We found that patients with recurrence showed high expression of miR-192-5p after tamoxifen treatments. In addition, expression of miR-500a-3p was significantly correlated to survival outcome. As miRNAs involved in the regulatory mechanism between LY6K and ERa can affect tamoxifen resistance, downregulating miR-192-5p or re-expressing miR-500a-3p could be a potential therapeutic approach for treating tamoxifen resistant patients.

\section{INTRODUCTION}

Breast cancer is the common malignant tumor world-wide in women. Classically, breast cancer is classified into several subgroups according to the expression of the following receptors: estrogen receptor (ER), progesterone receptor (PR) and human epidermal growth factor receptor 2 (HER2) [1]. Approximately $70 \%$ of breast cancer patients are dependent on estrogen receptor $\alpha(\mathrm{ER} \alpha)[2]$, so diverse treatment options have been developed targeting ER $\alpha$ [3], [4]. Tamoxifen is broadly used in adjuvant treatment for ER-positive breast cancer patients. In addition, Tamoxifen was clinically associated with growth arrest and apoptosis by interrupting estrogen binding to the ER in ER $\alpha$-positive breast cancer.
However, tumors that undergo loss of ER or negative expression of ER have less responsiveness to ER-targeted drugs in breast cancer [5].

Lymphocyte antigen 6 complex locus K (LY6K) is a member of the Ly-6/urokinase-type plasminogen activator receptor (UPAR) superfamily [6]. Recently, LY6K was reported to be a molecular biomarker in breast cancer [7], bladder cancer [8] and esophageal squamous cell carcinomas [9]. In addition, LY6K expression is regulated by the AP-1 transcription factor that promotes cell proliferation, invasive and metastatic abilities in breast cancer cells [10]. Nonetheless, there are few studies to supporting the effect of LY6K on various type of breast cancer.

A variety of cellular activities are regulated by MicroRNAs (miRNAs) such as apoptosis, metabolism 
and proliferation in many cancer types $[11,12]$. Recent studies have demonstrated that the expression of miRNAs is related to pathologic features in breast cancer [13]. miR-221/222 [14, 15] and miR-181 [16] contribute to the development of tamoxifen resistance by degrading genes involved in the regulation of breast cancer therapies. Furthermore, re-expression of miR-320a [17], miR-375 [18], and miR-342 [19] could restore tamoxifen sensitivity by inhibiting their targets.

In this study, we found an inverse correlation between the expression of ER $\alpha$ and LY6K in breast cancer. By investigating the molecular mechanism behind the functions of miR-192-5p and miR-500a-3p in the regulation of $\mathrm{ER} \alpha$ and $\mathrm{LY} 6 \mathrm{~K}$, how miR-192-5p, induced by LY6K, causes tamoxifen resistance by inhibiting ER $\alpha$ expression in ER $\alpha$-positive breast cancer. In addition, we elucidated the mechanism miR-500a-3p is induced by ER $\alpha$ and downregulates LY6K expression and re-expression of miR-500a-3p sensitizes tamoxifen responsivity. Our findings provides a rationale for downregulating miR-192-5p or re-expressing miR-500a-3p as a potential therapeutic strategy for treating tamoxifen resistant patients.

\section{RESULTS}

\section{LY6K and ER $\alpha$ is negatively expressed in breast cancer cells}

To investigate LY6K is involved in the regulation of $\mathrm{ER} \alpha$ expression, we evaluated both the mRNA and protein levels in the breast cancer cell lines. We confirmed that the ER $\alpha$-positive breast cancer cell lines, MCF7 and T47D, did not express LY6K mRNA and protein, whereas the ER $\alpha$-negative breast cancer cell lines, MCF7-ADR and MDA-MB-468, expressed LY6K mRNA and protein (Figure 1A and 1B). To confirm the inverse correlation between ER $\alpha$ and LY6K, we observed ER $\alpha$ expression by overexpressing LY6K in ER $\alpha$-positive breast cancer cell lines. Both ER $\alpha$ mRNA and protein were downregulated by LY6K (Figure 1C and D). In addition, we observed that the expression of LY6K was reduced by ectopic expression of ER $\alpha$ in MCF7-ADR and MDA-MB-468, well known as ER $\alpha$-negative breast cancer cells. Ectopic expression of $\mathrm{ER} \alpha$ led to the reduction of both LY6K mRNA and protein expression in ER $\alpha$-negative breast cancer cells (Figure 1E and $1 \mathrm{~F})$.

\section{LY6K and $E R \alpha$ expression is regulated in miRNA-dependent manner}

To identify the molecular events involved in the inverse correlation between LY6K and ER $\alpha$, we hypothesized that the upregulation of miRNA by LY6K and ER $\alpha$ might mediate the expression of target genes. To verify this hypothesis, we confirmed the level of $\mathrm{ER} \alpha$ expression level through simultaneously the overexpression of LY6K and knock-down of Argonate 2 (Ago2), which participates in mature miRNA processing as a member of the RNA-induced silencing (RISC) complex protein. As a result, the mRNA and protein expression level for $\mathrm{ER} \alpha$ reduced by ectopic expression of LY6K, whereas knock-down of Ago 2 restored the expression of ER $\alpha$ (Figure 2A and 2B). Furthermore, ectopic expression of ER $\alpha$ led to the reduction of LY6K expression but AGO2 knockdown did not further reduce LY6K expression in MCF7-ADR, MDA-MB-468 (Figure 2C and 2D). Collectively, these results indicated that the regulation mechanism for LY6K and ER $\alpha$ is dependent on miRNAs.

\section{LY6K and ER $\alpha$ affect miRNA expression in breast cancer cells}

On the basis of these observations, we further investigate to identify miRNAs affected by the overexpression of LY6K or ER $\alpha$. We first carried out miRNA microarray analysis in T47D, ER $\alpha$-positive cells, compared with T47D/LY6K (Supplementary Figure S1A). Another miRNA microarray analysis was performed in comparison with MCF7-ADR, ER $\alpha$-negative cells, MCF7$\mathrm{ADR} / \mathrm{ER} \alpha$, transiently overexpress ER $\alpha$. (Supplementary Figure S1B). As a result, we found several miRNA which were affected and upregulated by LY6K or ER $\alpha$. To search for miRNAs which directly target to ER $\alpha$ and LY6K 3' untranslated region (3'UTR), we used miRanda (http:// www.microrna.org) computational tools and identified candidate miRNAs.

To validate the miRNA microarray analysis, we explored the possibility that selected miRNAs were activated by transient overexpression of LY6K or ER $\alpha$ in each breast cancer cell. We first confirmed that all three primary-miRNA (pri-miRNA), activated by RNA Polymerase II binding to the relevant DNA sequence during miRNA biogenesis, were significantly increased (Figure 3A) and mature miRNA expression also increased (Figure $3 \mathrm{~B}$ and $3 \mathrm{C}$ ). These results revealed that selected miRNAs were transcriptionally activated by LY6K or $\mathrm{ER} \alpha$.

\section{miR-192-5p induced by LY6K suppresses ERa expression}

To determine whether the reduced expression of ER $\alpha$ was due to direct targeting among miR-29b-3p, miR29c-5p and miR-192-5p, we cloned luciferase reporter construct ESR1 3'-UTR containing the predicted binding site for each miRNA (Figure 4A and Supplementary Figure S2A). Among the selected miRNAs, only miR$192-5 p$ altered luciferase activity in wild type constructs when compared with the mutant type construct. Likewise, luciferase activity was reduced by the transfection of LY6K (Figure 4B). In the case of miR-29b-3p and miR$29 c-5 p$, luciferase activity was no different between the 
wild type reporter construct and in the mutant with regard to the predicted binding site following the transfection of each miRNA (Supplementary Figure S2B). In conclusion, the results of the dual luciferase assay confirmed that miR192-5p directly targets ESR1.

To assess a possible role for the downregulation of ER $\alpha$ in MCF7 and T47D, we transfected either a miR192-5p mimic (mimic) or a negative control mimic (NC). We confirmed the miR-192 expression using qRT-PCR after treating mimic (Supplementary Figure S3A). The mRNA and protein of ER $\alpha$ were significantly reduced by the overexpression of miR-192-5p in both MCF7 and T47D (Figure 4C). In addition, to observe whether the inhibition of miR-192-5p expression restored the mRNA expression of $\mathrm{ER} \alpha$, we generated a T47D stable cell line over-expressing human LY6K genes (T47D/LY6K) using G418 selection. It was confirmed that this stable cell line expressed plenty of LY6K mRNA and protein by qRTPCR and western blot, respectively (Figure 4D). By using T47D/LY6K cells, we repressed the expression of miR-192-5p and confirmed the level of miR-192-5p by qRT-PCR (Supplementary Figure S3B). Consequently, inhibition of miR-192-5p restored ER $\alpha$ mRNA expression. Likewise, the protein expression of ER $\alpha$ was upregulated by inhibiting miR-192-5p expression in T47D/LY6K stable cells (Figure 4E). Taken together, miR-192-5p, induced by LY6K, repressed the level of ER $\alpha$ expression.

\section{miR-500a-3p, induced by ERo, targets and inhibits human LY6K expression}

In the same context, to determine whether the reduced expression of LY6K was due to direct targeting among three selected miRNAs, we searched the 3'UTR region of the LY6K gene for the miRNA binding motif using miRnada program. We generated luciferase reporter constructs with human LY6K 3'UTR containing each miRNA (Figure 5A and Supplementary Figure S4A).
A

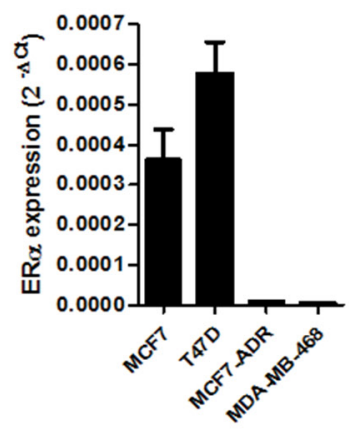

C
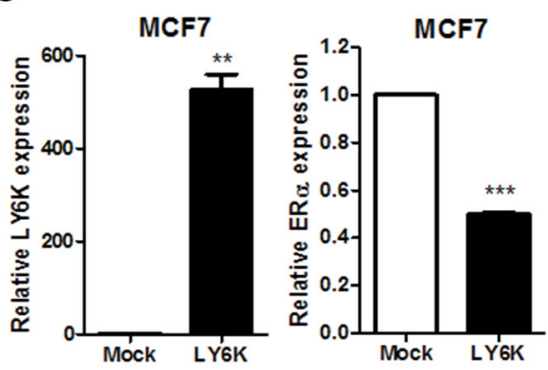

E
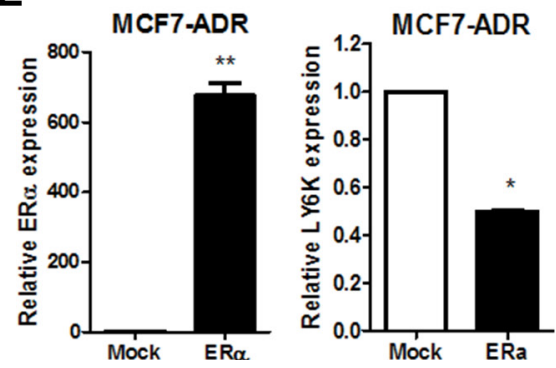
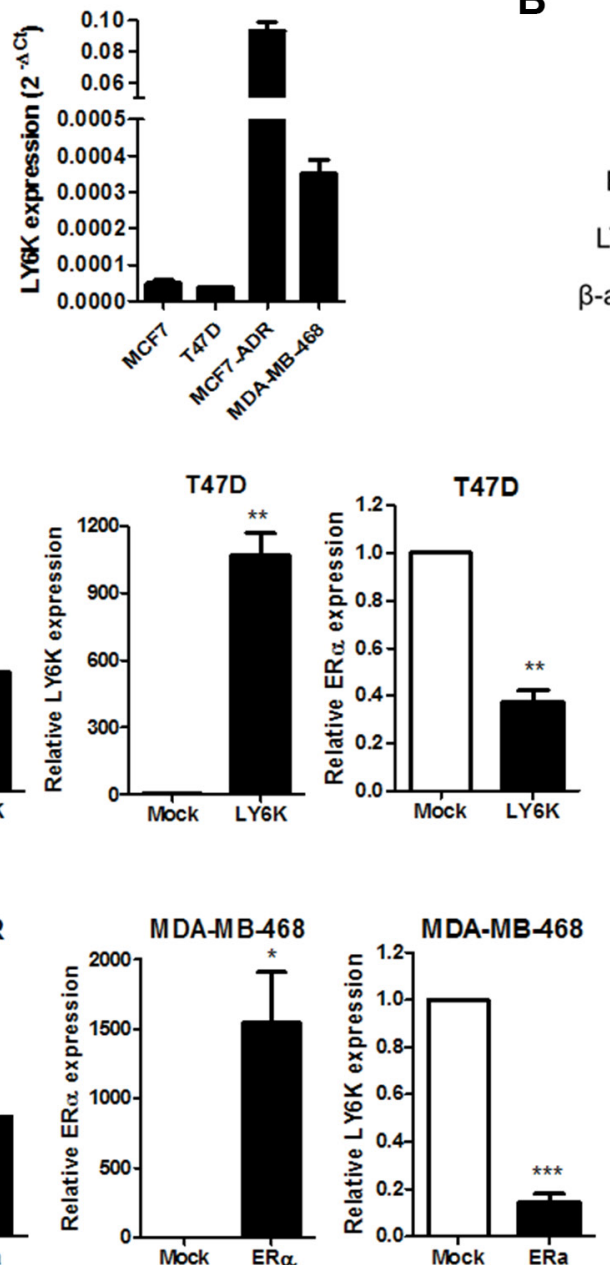

B

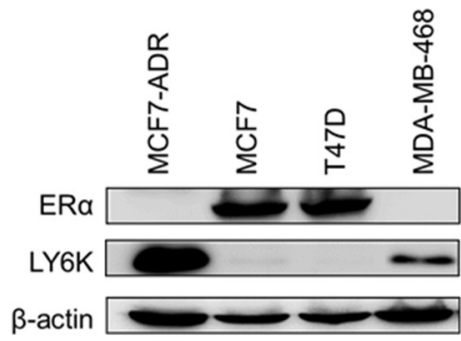

D

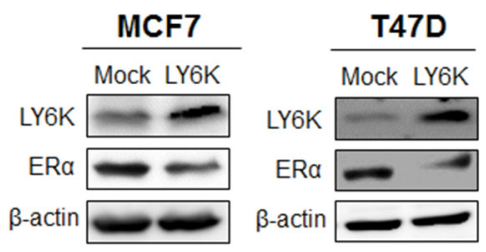

$\mathbf{F}$

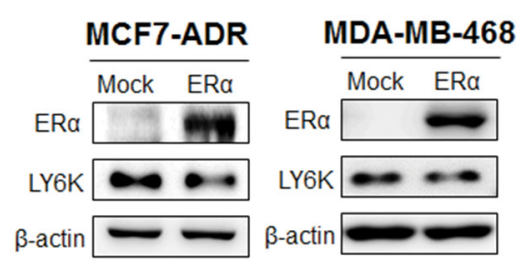

Figure 1: The expression of ER $\alpha$ is negatively correlated with LY6K. (A and B) Expression of LY6K and ER $\alpha$ mRNA and protein was observed by qRT-PCR using specific primers and western blotting. h18s rRNA and $\beta$-actin were used for endogenous control. (C and D) Ectopic expression of LY6K in MCF7 and T47D downregulated ER $\alpha$ transcriptional activity and protein expression. (E and F) Ectopic expression of ER $\alpha$ in MCF7-ADR and MDA-MB-468 reduce LY6K mRNA and protein expression. Data are a mean \pm S.D. (error bars) of three independent experiment in triplicate. ${ }^{* * *} p<0.001 ;{ }^{* *} p<0.01 ;{ }^{*} p<0.05$. 
Among these miRNA, only miR-500a-3p overexpression led to a decrease in luciferase activity. Luciferase activity was also reduced by ectopic expression of ER $\alpha$. This response was abrogated by the mutation of two miR-500a-3p targeted seed sequences (Figure 5B). The luciferase activity was no different between the wild type reporter construct and the mutant construct of the

A
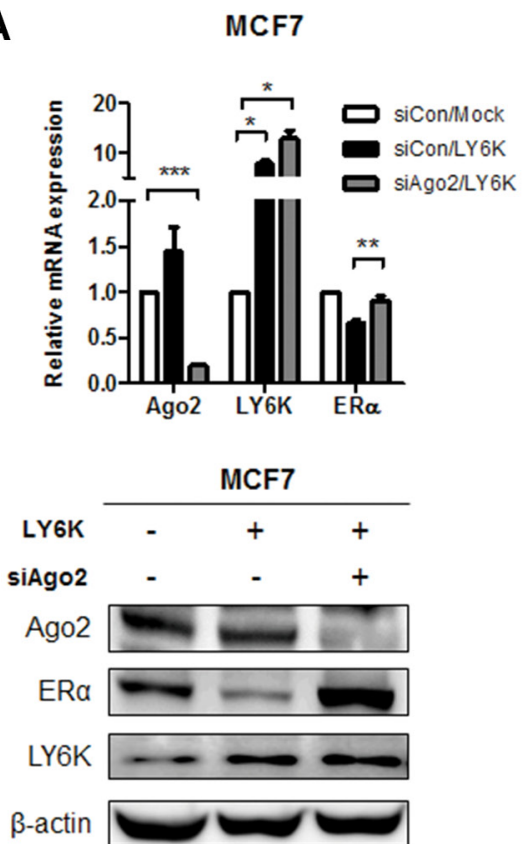

C

MCF7-ADR
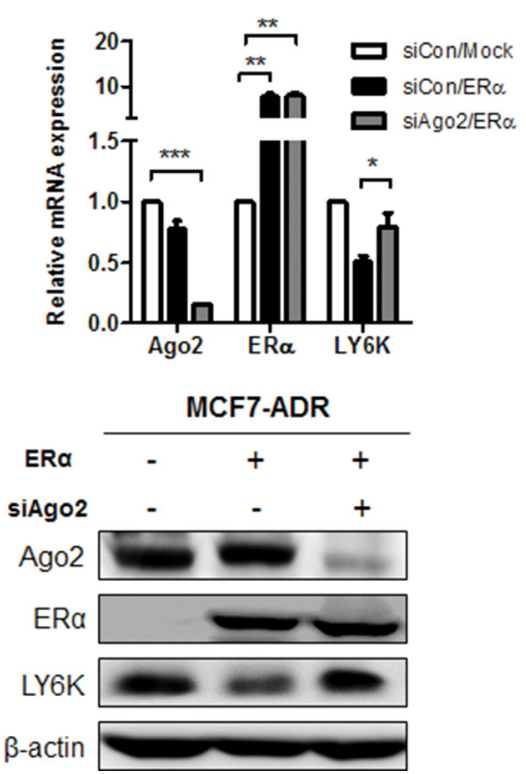

predicted binding site following the transfection miR-34a and miR-194-5p (Supplementary Figure S4B).

We further identified the possible role of LY6K downregulation by the overexpression of a miR-500a-3p mimic. We transfected the miR-500a-3p mimic (mimic) and the negative control mimic (NC). We confirmed that the transfection efficiency of the miR-500a-3p mimic

B

T47D
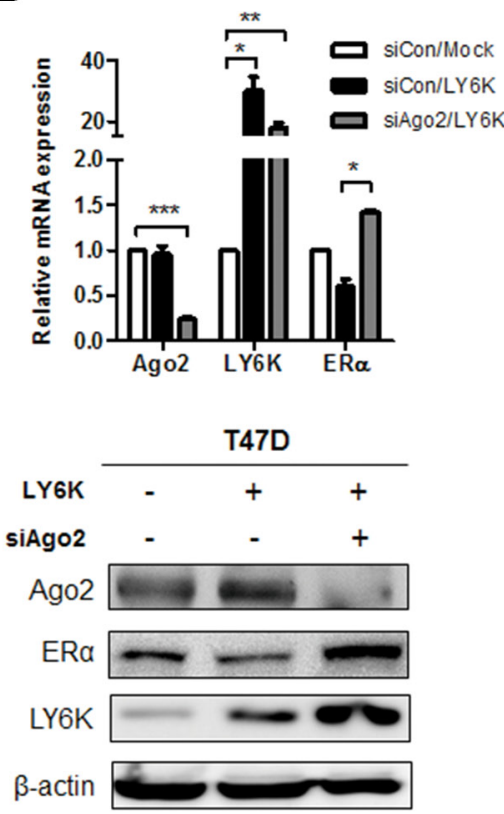

D
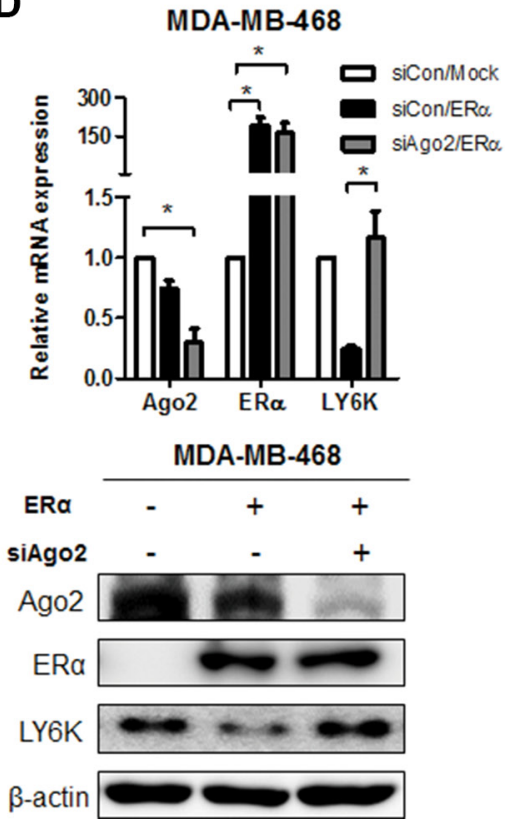

Figure 2: The regulation of ER $\alpha$ and LY6K expression in a miRNA-dependent manner. (A and B) Gene expression level was determined on both mRNA and Protein levels after treatment with Ago 2 siRNA combined with overexpression of LY6K for 48 hr. The expression of mRNA and protein was analyzed by qRT-PCR and western blotting. (C and D) LY6K expression in response to knock-down of AGO2 by treating with control and ER $\alpha$ for $48 \mathrm{hr}$. The expression of mRNA and protein was investigated by qRT-PCR and western blotting. Data are a mean \pm S.D. (error bars) of three independent experiment in triplicate. ${ }^{* * *} p<0.001 ;{ }^{*} p<0.01 ;{ }^{*} p<0.05$. 
using qRT-PCR (Supplementary Figure S3C). LY6K mRNA and protein expression was significantly reduced by ectopic miR-500a-3p in both MCF7-ADR and MDAMB-468 (Figure 5C). These results suggested that miR-500a-3p, induced by ER $\alpha$, directly repressed LY6K expression.

\section{A}

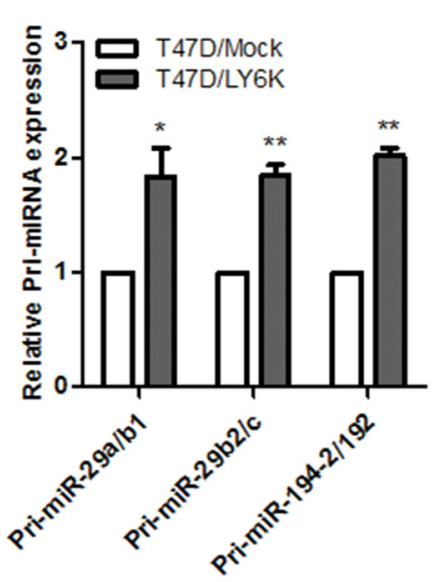

B

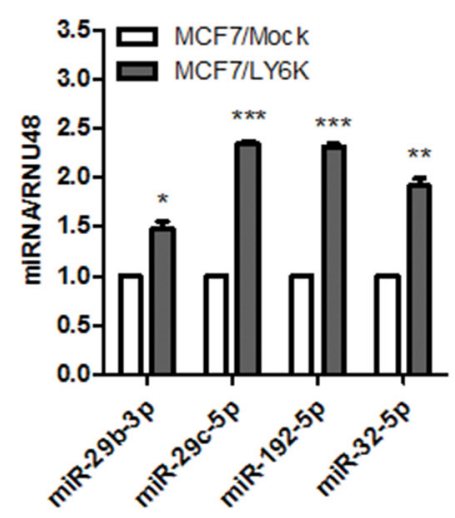

C

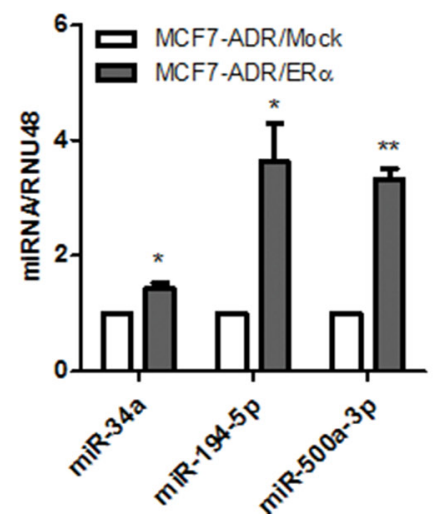

Inhibition of miR-192-5p sensitizes resistance to tamoxifen in breast cancer cells

Having demonstrated the miRNA-dependent reciprocal regulation of $\mathrm{LY} 6 \mathrm{~K}$ and $\mathrm{ER} \alpha$ expression, we further studied whether miR-192-5p and miR-500a-3p
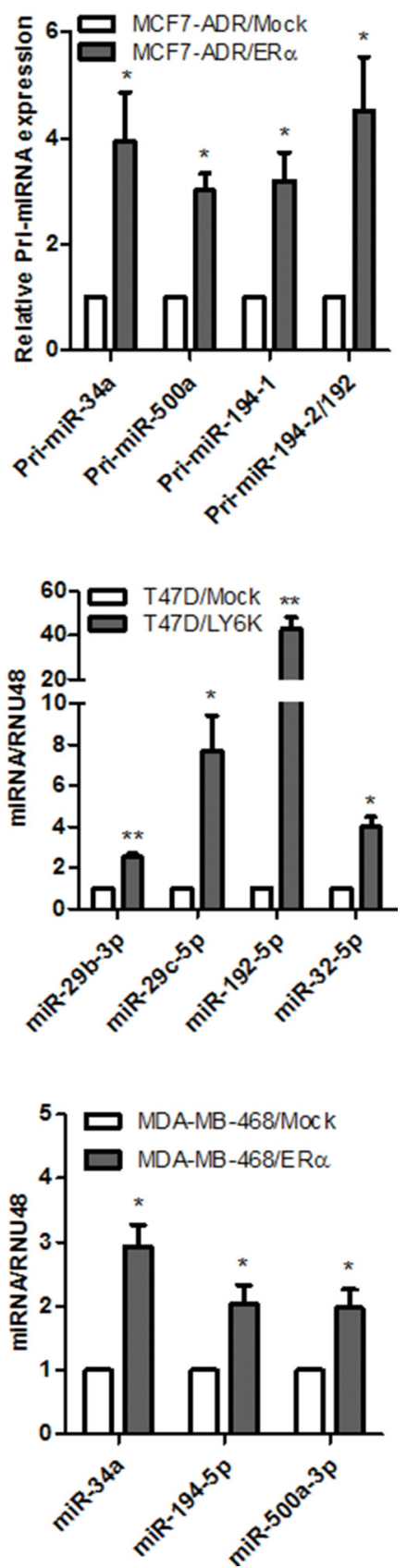

Figure 3: Validation of primary and mature miRNAs induced by LY6K or ER $\alpha$. (A) Validation of upregulated primary miRNA (pri-miRNA) expression in T47D/LY6K was compared with T47D/Mock (left) and MCF7-ADR/Mock compared with MCF7ADR/ER $\alpha$ (right) by using qRT-PCR. Each primary miRNA produces mature miRNAs (Pri-miR-29a/b1: miR-29b, Pri-miR29b2/c: miR-29b and miR-29c, Pri-miR-194-2/192: miR-192-5p and miR-194, Pri-miR-194-1: miR-194, Pri-miR-34a: miR-34a, Pri-miR-500a: miR-500a-5p or -3p). (B) Verification of miRNA expression induced by LY6K in ER $\alpha$-positive breast cancer cell lines, MCF7 (left) and T47D (right). (C) Verification of mature miRNA induced by ER $\alpha$ in ER $\alpha$-negative breast cancer cell lines, MCF7-ADR (left) and MDAMB-468 (right). Data are a mean \pm S.D. (error bars) of three independent experiment in triplicate. ${ }^{* * *} p<0.001 ;{ }^{* *} p<0.01 ;{ }^{*} p<0.05$. 
are functionally involved in tamoxifen responsiveness in breast cancer. This is because tamoxifen is a selective estrogen antagonist and a well-known drug for breast cancer. To identify whether T47D/LY6K cells had tamoxifen resistance, we evaluated the cell viability after treating T47D and T47D/LY6K cell with tamoxifen. The cell viability was significantly reduced in T47D cells after treatment with tamoxifen whereas, the cell viability was barely reduced in T47D/LY6K because ER $\alpha$ expression was suppressed (Supplementary Figure S5A). Moreover, compared to the negative miRNA inhibitor (NC), inhibition of the miR-192-5p expression made T47D/LY6K cells more susceptible to tamoxifen (Figure 6A).

Tamoxifen was also reported to induce apoptosis and to inhibit cell proliferation in breast cancer cells [20]. After treating T47D and T47D/LY6K cells with tamoxifen, Caspase- 3 activation was significantly increased in T47D cells but was relatively low in T47D/LY6K (Supplementary Figure S4B). Since the inhibition of miR-192-5p in T47D/ LY6K affected cell viability, we further investigated the effect of tamoxifen-induced apoptosis by inhibiting the activity of miR-192-5p. Caspase-3 activity was increased by treatment with the miR-192-5p inhibitor in comparison

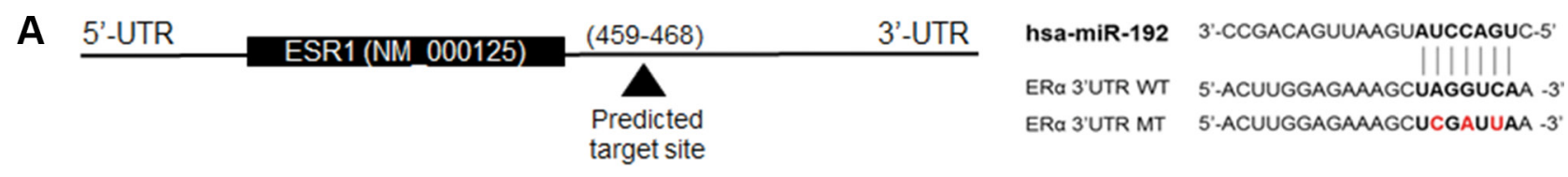

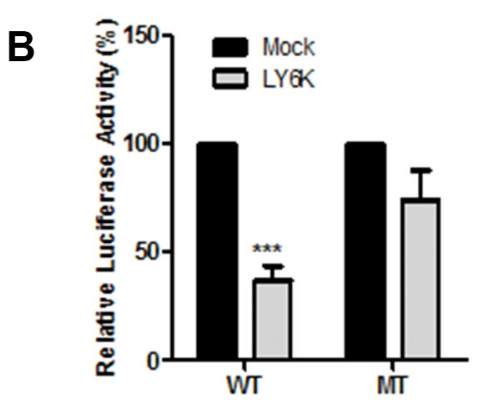

miR-192 predicted binding site on ER $\alpha$ 3'UTR

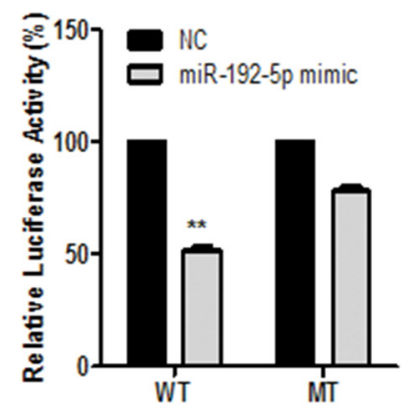

miR-192 predicted binding site on ER $\alpha$ 3UTR
C
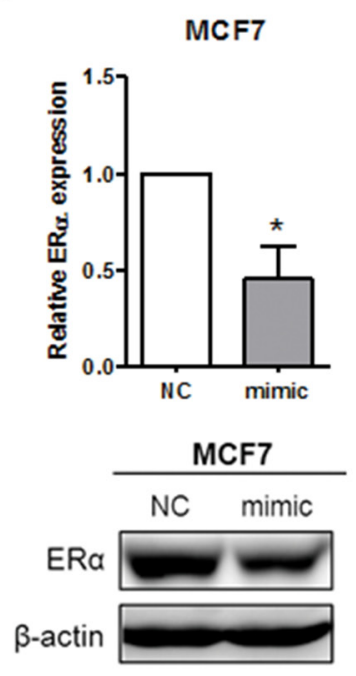

D

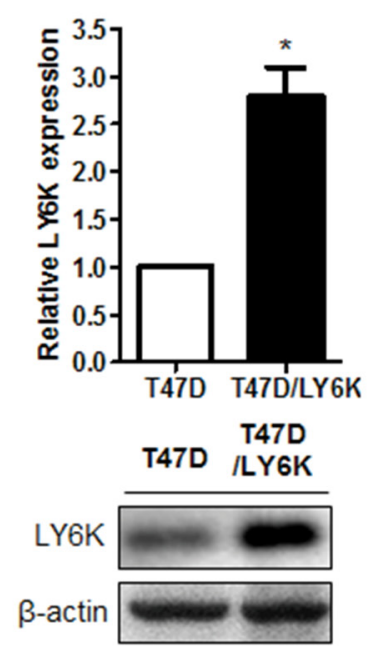

E

T47D
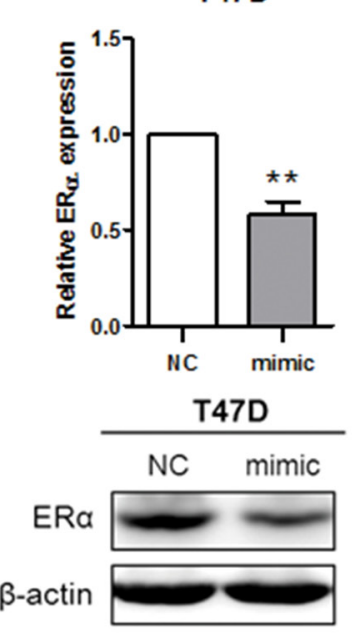
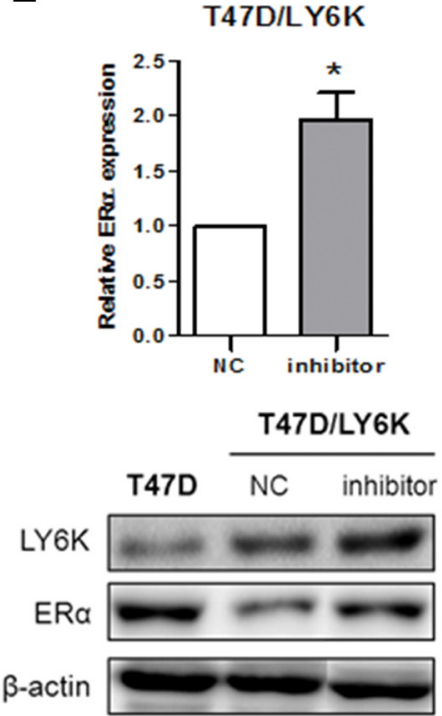

Figure 4: miR-192-5p directly binds ERa 3'UTR and regulates its expression. (A) Gene structure of ESR1 showing the predicted target site of miR-192-5p in its 3'-UTR. (B) Luciferase assay in MCF7 cells showed miR-192-5p dependent repression of wild type (WT) ER a 3'UTR (left), whereas mutation (MT) of the miR-192-5p predicted binding site did not affect repression (right). (C) Re-expression of miR-192-5p repressed the mRNA and protein expression of ER $\alpha$ in MCF7 and T47D. (D) mRNA and Protein expression of LY6K was determined in Human LY6K over-expressing stable cell line by qRT-PCR and western blot. (E) Inhibition of miR-192-5p expression increases ER $\alpha$ expression in T47D/LY6K stable cells. Mimic, miR-192-5p mimic treated cell; inhibitor, miR-192 inhibitor treated cell. Data present mean \pm S.D. (error bars) of three independent experiments in triplicate. ${ }^{* * *} p<0.001 ; * * p<0.01$. 
with the negative miRNA inhibitor (NC) after incubating T47D/LY6K cells with tamoxifen (Figure 6B).

In addition, to confirm whether miR-192$5 \mathrm{p}$ enhancement induced tamoxifen resistance, we investigated that sub G1 phase of cell cycle after treatment of 4-OHT with miR-192-5p. The apoptotic cells was reduced by ectopic miR-192-5p in T47D cells (Figure 6C), suggesting that the miR-192-5p suppressed tamoxifeninduced apoptosis. From these results, miR-192-5p appears to regulate resistance to tamoxifen through cell viability along with cell apoptosis.

\section{miR-500a-3p enhances tamoxifen sensitivity by promoting apoptosis in breast cancer cells}

We have shown that miR-500a-3p downregulates LY6K expression by directly targeting its 3'UTR. In this study, we investigated miR-500a-3p enforced tamoxifen sensitivity through the activation of apoptosis in ER $\alpha$ negative cancer cells. This is because tamoxifen is effective in ER $\alpha$-positive breast cancer patients but only $10 \sim 15 \%$ of $E R \alpha$ - negative patients respond to tamoxifen. We assessed cell viability by treatment with tamoxifen to transiently miR-500a-3p overexpression in MCF7-ADR. The cell viability was significantly reduced by ectopic expression of miR-500a-3p in MCF7-ADR (Figure 6D).
In addition, we examined the effect of miR-500a-3p reexpression on enhancing tamoxifen sensitivity through apoptosis. miR-500a-3p significantly affected caspase-3 activation after treatment with tamoxifen $(10 \mu \mathrm{M})$ compared to negative control (NC) (Figure 6E). Similar results were also found cells analysis in the sub-G1 phase of the cell cycle after treatment of tamoxifen using flow cytometry. Ectopic expression of miR-500a-3p was found to promote tamoxifen-induced apoptosis in MCF7-ADR (Figure 6F). The results together indicate that miR-500a$3 p$, induced by $E R \alpha$, regulates tamoxifen sensitivity by targeting LY6K in ER $\alpha$-negative breast cancer cells.

\section{miRNAs involved in the mechanism of LY6K and $E R \alpha$ are related to tamoxifen susceptibility in breast cancer patients.}

We have shown that LY6K and ER $\alpha$ have an inverse correlation in breast cancer and that miRNAs involved in this mechanism affect tamoxifen resistance. To further ascertain whether miRNAs involved in the mechanism for LY6K and ER $\alpha$ are correlated with clinical outcomes in breast cancer patients, we first investigated the inverse correlation between LY6K and ER $\alpha$ expression in breast primary tumor samples obtained from oncomine ${ }^{\mathrm{TM}}$. ER positive tumors had relatively low LY6K expression
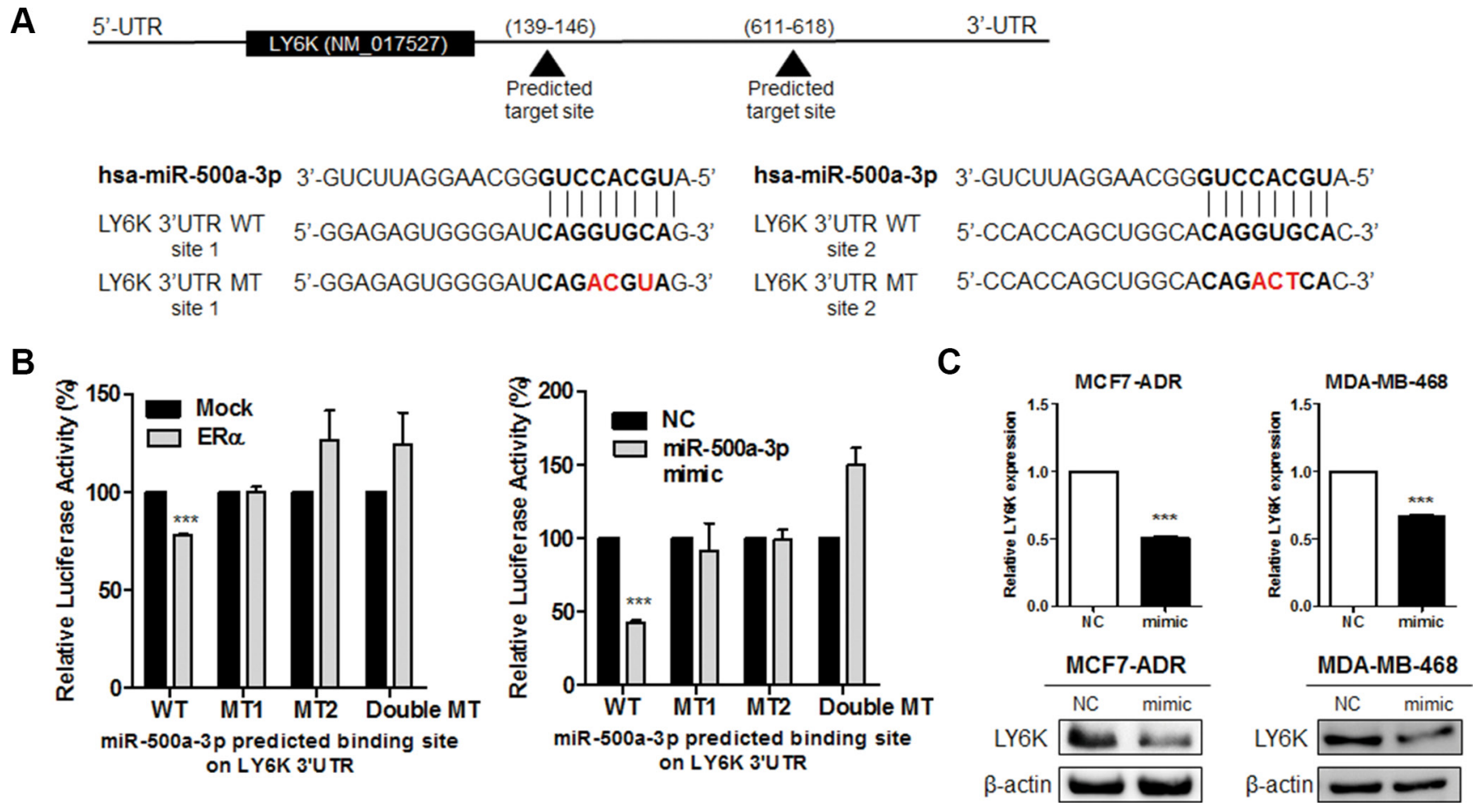

Figure 5: LY6K is a direct target of miR-500a-3p and down regulates its expression. (A) Gene structure of LY6K showing the two predicted target sites of miR-500a-3p in its 3'UTR. (B) Dual Luciferase assay in HEK293T cells showed ER $\alpha$ (left) and miR-500a$3 p$ (right) dependent inhibition of wild type (WT) LY6K 3'-UTR, whereas the mutant type (MT) seed sequence restored luciferase activity. (C) Ectopic expression of miR-500a-3p represses LY6K mRNA and protein expression in MCF7-ADR (left) and MDA-MB-468 (right). NC, miRNA negative control; mimic, miRNA mimic. Data represent mean \pm S.D. (error bars) of three independent experiment in triplicate. $* * * p<0.001$. 
while ER negative tumors showed high LY6K expression (Figure 7A). In addition, we observed miR-192-5p and miR-500a-3p expression in primary breast tumors treated with tamoxifen. Patients with recurrence showed increased miR-192-5p expression (Figure 7B). These results suggested that increasing expression of miR-192-5p could
A

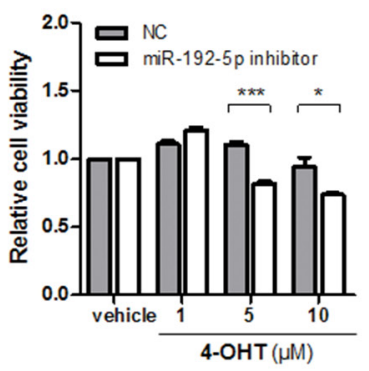

B

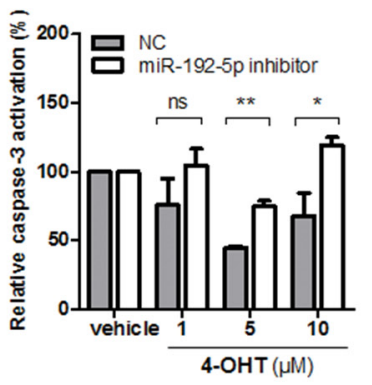

D

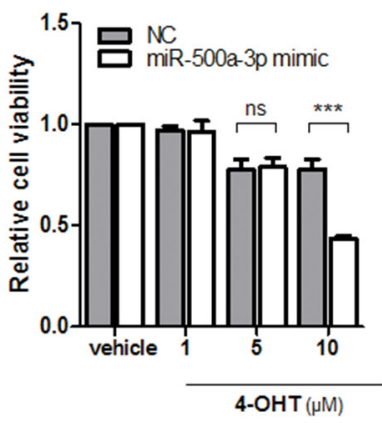

E

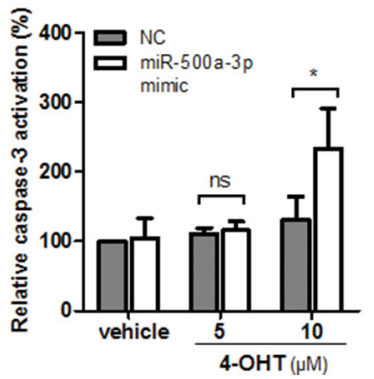

C
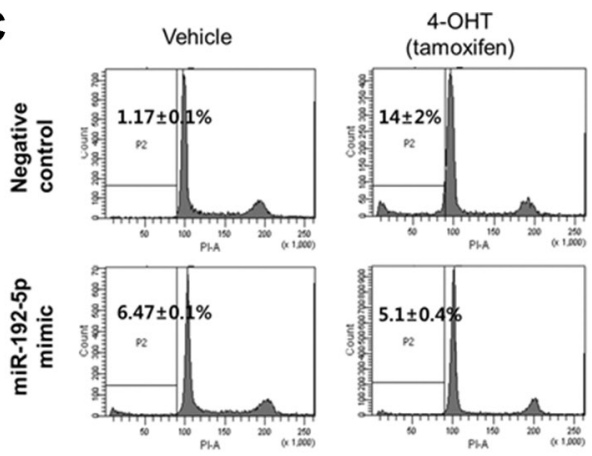

DNA-content (Propidium iodide-stained)

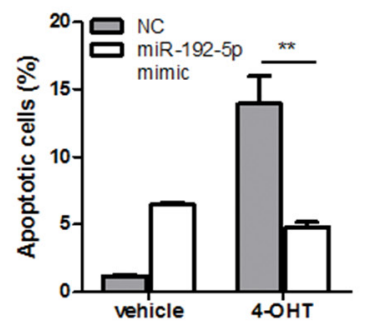

$\mathbf{F}$
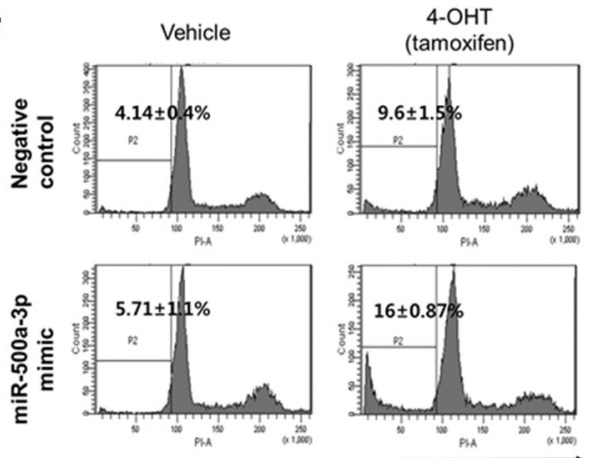

DNA-content (Propidium iodide-stained)

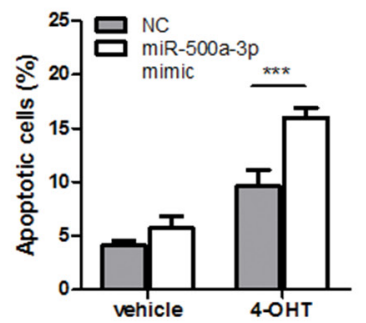

Figure 6: miR-192-5p and miR-500a-3p mediates tamoxifen sensitivity in breast cancer. (A) Cell viability after transfection with miR-negative control inhibitor (NC) and miR-192-5p inhibitor in stably overexpressing LY6K (T47D/LY6K) cells was measured 3 hours after treatment with 4-OHT in a dose-dependent manner. (B) Caspase-3 activity was determined in T47D/LY6K transfected with miR-negative control inhibitor (NC) or miR-192-5p inhibitor after incubating with vehicle or 4-OHT (1, 5, $10 \mu \mathrm{M})$ for 3 hours. (C) T47D cells with miR-192-5p mimic transfected and then treated with 4-OHT ( $5 \mu \mathrm{M})$ for $24 \mathrm{hr}$. Apoptotic cells were assayed by flow cytometry sub-G1 analysis. (D) Cell viability with miR-negative control (NC) or miR-500a-3p was measured after 24 hr incubation with various doses of 4-OHT in MCF7-ADR. (E) Caspase-3 activation was increased by miR-500a-3p after $48 \mathrm{hr}$ treatment with vehicle or 4-OHT. (F) MCF7-ADR cells with miR-500a-3p mimic transfected and then treated with 4-OHT $(10 \mu \mathrm{M})$ for $24 \mathrm{hr}$. Apoptotic cells were determined by flow cytometry (sub-G1 analysis of PI staining). The graph shows the mean \pm S.D. (error bars) of three independent experiments. $* * * p<0.001 ; * * p<0.01 ; * p<0.05 ;$ ns, non-specific. 
lead to recurrence in ER $\alpha$-positive breast cancer patients because reduced expression of ER $\alpha$ is one of the causes of tamoxifen resistance. Although miR-500a-3p expression was not significantly different in recurrence (Figure 7C), expression of miR-500a-3p was significantly correlated with survival outcome in breast cancer patients treated with tamoxifen (Figure 7D).

In conclusion, the expression of miR-192-5p is upregulated because of increased LY6K in ER $\alpha$-positive and LY6K-negative breast cancer. The expression of miR-500a-3p is also up-regulated by ER $\alpha$ overexpression in LY6K-positive and ER $\alpha$-negative breast cancer. Increased expression of miR-192-5p leads to decreased ER $\alpha$ expression, which is one of the problems that lead to tamoxifen resistance in ER $\alpha$-positive cancer. In addition, upregulated miR-500a-3p expression, instead of ER $\alpha$ restoration, can affect tamoxifen susceptibility by targeting LY6K in ER $\alpha$-negative breast cancer (Figure 7E).

\section{DISCUSSION}

In our data, we clearly found that the expression of LY6K and ER $\alpha$ is negatively correlated in breast cancer cells. We observed the down-regulation of ER $\alpha$ expression when overexpressing the human LY6K gene in ER $\alpha$ positive cells (Figure 1C and 1D). Among the different causes of resistance to hormonal therapies, the loss of ER $\alpha$ expression is an important factor in breast cancer [21]. This reduced expression of ER $\alpha$ brought by LY6K may provide a clue for patients that develop resistance to hormonal therapies. In addition, LY6K expression is downregulated by ectopic expression of ER $\alpha$ (Figure 1E and 1F). It was reported that highly upregulated LY6K is related to cell proliferation and metastatic abilities in breast cancer [10]. These findings suggested that $\mathrm{ER} \alpha$ could be involved in attenuating metastatic and proliferative capacities and may enhance drug sensitivities in ER $\alpha$-negative breast cancer.
A

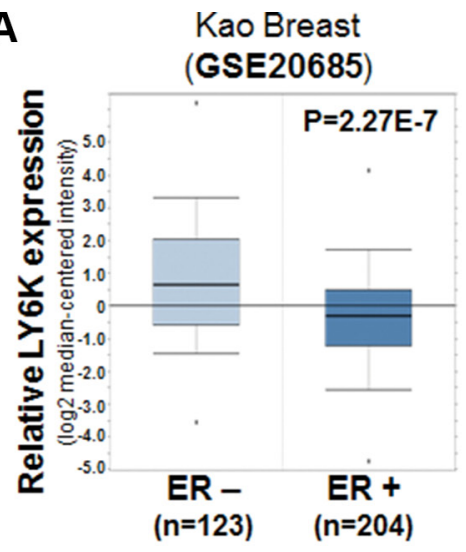

D

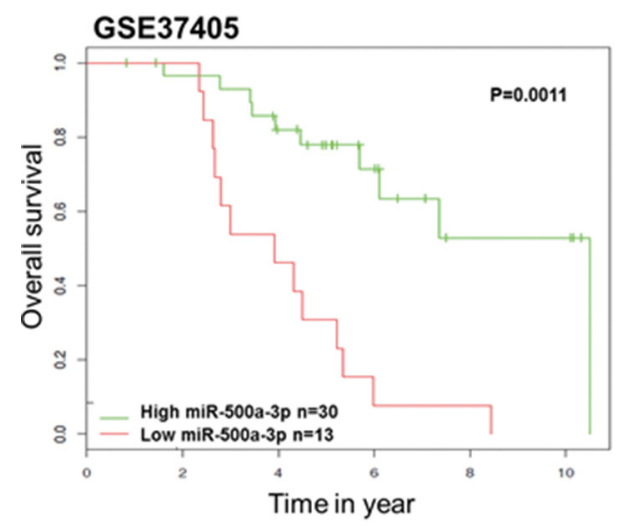

B

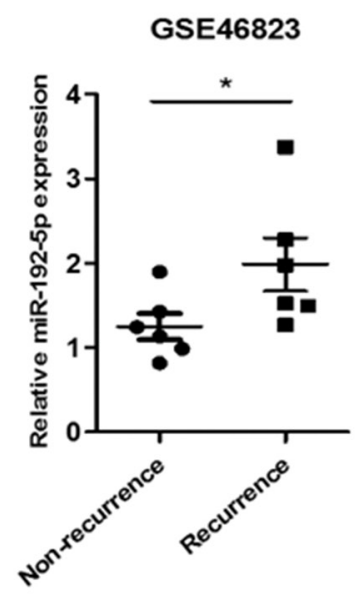

E

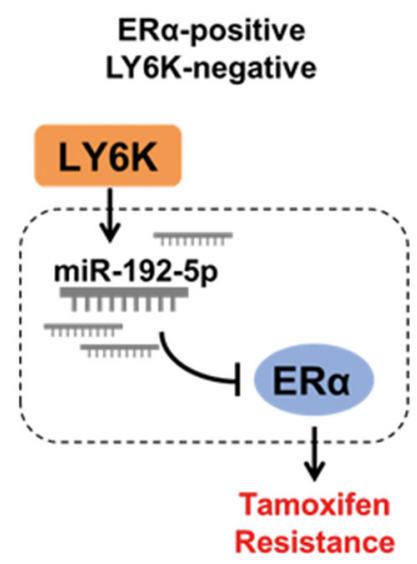

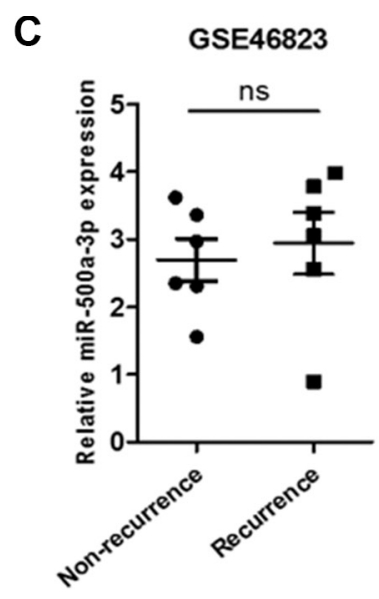
ER $\alpha$-negative
LY6K-positive

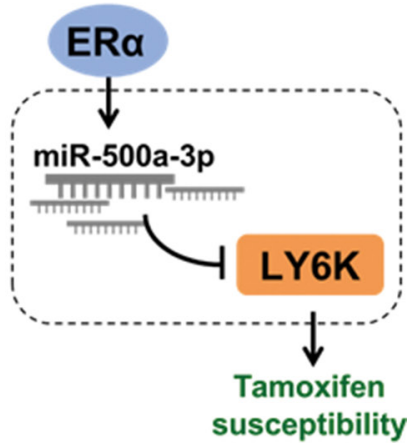

Figure 7: miR-192-5p and miR-500a-3p involved in LY6K and ER $\alpha$ are related to tamoxifen resistance in breast cancer patients. (A) The relative LY6K expression depending on ER status in kao-breast cancer from oncomine ${ }^{\mathrm{TM}}$. (B) $\mathrm{miR}-192-5 \mathrm{p}$ expression in non-recurrence and recurrence primary breast tumors after tamoxifen treatment. The data were obtained from GSE 46823 (C) miR-500a-3p expression showed non-significant differences between non-recurrence and recurrence primary breast tumors after tamoxifen treatment. The data were obtained from GSE 46823. (D) Low expression of miR-500a-3p was correlated with poor survival outcomes in breast cancer patients received tamoxifen mono-therapy. (E) Hypothetical schematic pathway image. The mechanism for miR-192-5p and miR-500a-3p effects on tamoxifen susceptibility through the regulation of target genes in breast cancer. $* P<0.05$; ns, non-significant. 
It is widely known that miRNA is important as an oncogene or a tumor suppressor gene depending on the subtypes of a particular cancer [22]. Here, we showed that miR-192-5p, induced by LY6K, and miR-500a-3, induced by $\mathrm{ER} \alpha$, were selected through microRNA microarray (Figure 3 and Supplementary Figure S1). Elevated LY6K activated matrix metalloproteinase proteins MMP-2 and MMP-9 [23]. The expression of miR-192-5p is transcriptionally activated by TGF-beta, which well known as growth factor stimulated by MMPs [24, 25]. Although LY6K is not known as a transcriptional factor, transcription of miR-192-5p might be indirectly promoted by ectopic expression of LY6K. Recently, miR-192-5p was also identified as a potential target for esophageal cancer cells in a study profiling the development of chemotherapy resistance [26]. We observed that miR-192-5p was related to tamoxifen resistance through cell viability and apoptosis in breast cancer cells (Figure 6). In addition, miR-192$5 p$ expression was increased in primary tumor samples treated with tamoxifen (Figure 7), so inhibition of miR$192-5 p$ could be a potential therapeutic approach for the treatment of tamoxifen resistant breast cancer.

Furthermore, we determined that elevated ER $\alpha$ stimulates miR-500a-3p and suppress LY6K expression in ER $\alpha$-negative breast cancer cells (Figure 3 and Figure 5). Many studies have attempted to restore ER $\alpha$ expression in order to increase tamoxifen sensitivity in ER $\alpha$-negative breast cancer. HDAC inhibitors can induce re-expression of $\mathrm{ER} \alpha$ transcriptional activity and improve endocrine therapy when combined with DNA-damaging agents [27]. CpG methylation of the ER promoter by inhibition of DMNT activity can reactivate ER because of transcriptional silencing in ER $\alpha$-negative breast cancer cells [28, 29]. Similarly, our results suggested a novel mechanism involving the downregulation of LY6K via the miR-500a-3p axis, induced by ER $\alpha$, and may be involved in attenuating metastatic and proliferate capacities in ER $\alpha$-negative breast cancer. In this respect, upregulation miR-500a-3p may increase tamoxifen susceptibility because restoration of $\mathrm{ER} \alpha$ leads to increase miR-500a-3p expression about 2 3 times (Figure 3C and Supplementary Figure 1). Although there are no significant differences in tamoxifen resistant tumor samples (Figure 7C), these results were not clearly in accord with the environment that miR-500a-3p activities are increased by overexpression of ER $\alpha$. Also, low expression of miR$500 \mathrm{a}-3 \mathrm{p}$ is correlated to poor survival outcome in breast cancer patients who receiving tamoxifen mono therapy (Figure 7D). Thus, miR-500a-3p may help to increase tamoxifen susceptibility in breast cancer.

In conclusion, we showed for the first time that the involvement of miR-192-5p and miR-500a-3p regulates the mechanism for the interaction between ER $\alpha$ and LY6K and is related to tamoxifen responsiveness in breast cancer. These findings describe not only the loss of ER $\alpha$ correlated with miR-192-5p, induced by LY6K, in ER $\alpha$-positive breast cancer but also how upregulation of miR-500a-3p affects tamoxifen-induced cell death in ER $\alpha$-negative breast cancer. These results provide clues that not only the molecular mechanism of LY6K and ER $\alpha$ in breast cancer but also the inhibition of miR-192-5p in ER $\alpha$-positive breast cancer and the overexpression of miR-500a-3p in ER $\alpha$-negative breast cancer could be effective therapeutic agents.

\section{MATERIALS AND METHODS}

\section{Cell culture and plasmid transfection}

MCF7 and MDA-MB-468 cells were provided by Sapporo Medical University in December, 2010. Human breast carcinoma MCF7-ADR cell was obtained from Dr. YM Park (Roswell Park Cancer Institute, Buffalo) in 2006. These cells were tested by short tandem repeat marker for DNA fingerprinting analysis (Korean Cell Line Bank); Both MCF7 and MCF7-ADR were lastly tested in August, 2014; MDA-MB-468 in September, 2014. T47D cells were purchased from ATCC (Manassas, VA) in January, 2015. T47D cell was characterized and authenticated in the Cell Biology collection using short tandem repeat DNA profiles. Breast cancer cells experimented in this study were maintained in Dulbecco's modified Eagle's medium (WELGENE Inc, Korea) supplemented with 10\% fetal bovine serum (FBS) (Gibco ${ }^{\circledR}$, USA) in a $37^{\circ} \mathrm{C}$ humidified incubator and an atmosphere of 5\% CO2. A T47D stable cell line overexpressing the human LY6K gene was produced by G418 selection. Firstly, selected concentration for stable cells was $2 \mathrm{mg} / \mathrm{ml}$. After selection, G418 concentration was reduced from $1 \mathrm{mg} / \mathrm{ml}$ to $500 \mathrm{ug} / \mathrm{ml}$ and then $200 \mathrm{ug} / \mathrm{ml}$. The maintaining concentration of G418 was $200 \mathrm{ug} / \mathrm{ml}$.

MCF7 and T47D were transfected for $48 \mathrm{hrs}$ with hLY6K/pCMV6-Entry clone purchased from Origene. MCF7-ADR and MDA-MB-468 were transfected with human ER $\alpha /$ pCMV plasmid using Fugene $^{\circledR}$ reagent (Promega) according to the manufacturer's instructions. After 48 hours, the breast cancer cells were harvested and separated for qRT-PCR and Western blot analysis.

\section{Co-transfection with plasmid and small interfering RNA}

MCF7 and T47D cells were transfected with Argonatue 2 siRNA (SMARTpooled, Dharmacon) and human LY6K clone purchased from Origene Technologies using Lipofectamin 2000 (Invitrogen, USA) for 48 hours following by the manufacturer's instructions. MCF7ADR and MDA-MB-468 cells were co-transfected with Argonatue 2 siRNA (Dharmacon, USA) and human ER $\alpha$ clone in the same manner. Transfection of both scrambled siRNA (Dharmacon, USA) and pCMV-Flag plasmid was used as the control experiments. 


\section{Transfection of miRNA mimics and inhibitor}

MCF7 and T47D were reverse-transfected with a miRVana $^{\mathrm{TM}}$ miR-192p mimic (Ambion, USA) at a final concentration of $15 \mathrm{nM}$ or $30 \mathrm{nM}$ using the SiPORT ${ }^{\mathrm{TM}}$ NeoFX ${ }^{\mathrm{TM}}$ Transfection agent (Ambion, USA) according to the manufacturer's instructions. MCF7-ADR and MDA-MB-468 cells were reverse-transfected in the same manner. The control experiments were transfected with a miRVana ${ }^{\mathrm{TM}}$ miR-negative control mimic (Negative control \#1, Ambion, USA).

\section{Total RNA isolation and miRNA RT-PCR}

Total RNAs for the miRNA-microarray were isolated using Trizol ${ }^{\circledR}$ (Ambion, USA) as described in the manufacturer's instructions. We extracted total RNA including miRNA and other small RNAs from cultured cells with the miRNeasy RNA isolation kit (Qiagen). $500 \mathrm{ng}$ of total RNA was reverse transcribed with the TaqMan ${ }^{\mathbb{R}}$ MicroRNA Reverse Transcription Kit (Applied Biosystems) for has-miR-192-5p or has-miR-500a-3p detection.

\section{Quantitative RT-PCR (qRT-PCR)}

Quantitative RT-PCR for miRNA expression analysis was performed with the TaqMan ${ }^{\circledR}$ Universal PCR Master Mix (Applied Biosystems) using the LightCycler ${ }^{\circledR}$ System (Roche) and RNU48 was used as an internal control. Quantitative RT-PCR for mRNAs were extracted using the NucleoSpin ${ }^{\circledR}$ RNA/Protein kit (MACHEREYNAGEL). $5 \mu \mathrm{g}$ of mRNAs were reverse-transcribed by using M-MLV Reverse Transcriptase (Promega, USA), $10 \mathrm{pM}$ oligo-dT, $2.5 \mathrm{nM}$ dNTP mixture and RNAse inhibitor and each target gene was detected by using specific primers. PCR primer sequence were Human $\mathrm{ER} \alpha$, forward 5'- GGCCCAGCTC CTCCTCATG - 3'and reverse 5' - AGTGGCTTTGGTCCGTCTCC - 3' ; Human LY6K, forward 5'- AGCCCATGCCCTTCTTTTAC $-3^{\prime}$ and reverse 5' - CCAGCCACAGCCCACCACAG - 3'; Human Argonaute 2 (Ago2), forward: 5' - CTAGACCCGACTT TGGGACCT - $3^{\prime}$ and reverse 5'- GGGCACTTCTCTGGC TTGATA -3' ; Human 18s rRNA, forward 5'-GTCGGCG TCCCCCAACTTCTT $-3^{\prime}$ and reverse $5^{\prime}$ - CGTGCAGC CCCGGACATCTA -3' Human 18s rRNA was used as a housekeeping gene.

\section{Western blotting}

Proteins were isolated using the NucleoSpin ${ }^{\circledR}$ RNA/ Protein kit (MACHEREY-NAGEL). Protein contents were measured using Bicinchoninic acid Solution (Sigma, USA) and Copper (II) sulfate solution (Sigma, USA). Protein were separated on $12 \%$ or $8 \%$ SDS-PAGE gel. Western blotting of SDS-PAGE gels was performed using standard methodology. Primary antibodies were diluted at 1:1000 in 1\% skim milk in PBST. Primary antibodies used in this study were LY6K (Santa Cruz Biotechnology, USA), ER $\alpha$ (Santa Cruz Biotechnology, USA), Argonate2 (abcam ${ }^{\circledR}$, UK) and $\beta$-actin (Bethyl Laboratories, US). $\beta$-actin was used as a loading control. Immunoreactive proteins were detected by horseradish peroxidase-conjugated secondary antibodies and the enhanced chemiluminescence reagent, EzWestLumi plus (ATTO, JAPAN).

\section{Dual-Luciferase reporter assay}

The 3'UTR of human ER $\alpha$ was cloned into the XbaI site of the pGL3-control vector (Proemega, USA). The seed sequence of miR-29b-3p, miR-29c-5p and miR-192$5 \mathrm{p}$ on human ER $\alpha$ 3'UTR was mutated by with a PCRbased approach. We transfected luciferase constructs (1.8 $\mu \mathrm{g}$ of reporter gene/well in 6-well plate) and either human LY6K clones (200 ng/well in 6-well plate) or 30 nM of miRNA mimics into MCF7 cells using Lipofectamin 2000 (Invitrogen, USA). Human LY6K 3'UTR that included the predicted miR-500a-3p seed sequences into psiCHECK $^{\mathrm{TM}_{-} 2}$ vector (Promega, USA) using the Infusion ${ }^{\circledR}$ HD Cloning Kit (Clontech Laboratories, USA). The seed sequence for miR-500a-3p on LY6K 3'UTR was mutated by using the QuickChange II XL Site-Directed Mutagenesis Kit (Agilent Technologies, USA). We transfected HEK293T cells with the luciferase reporter constructs containing the LY6K 3'UTR variants and $30 \mathrm{nM}$ of miR-500a-3p mimics or negative control miRNA using Lipofectamin 2000 (Invitrogen, USA). After 48 hours, all experimental cells were passively lysed and measured with the Dual Luciferase Assay System (Promega, USA).

\section{Cell viability assay}

T47D and T47D/LY6K cells were seed at $1 \times 10^{4}$ cell/well in 96-well plates. Cell were incubated with 4-Hydroxytamoxifen (4-OHT; Sigma, USA) for $3 \mathrm{hr}$. T47D/LY6K cells were seeded and transfected with miR-192-5p inhibitor or a negative control inhibitor at a final concentration of $30 \mathrm{nM}$ using SiPORT ${ }^{\mathrm{TM}}$ neoTX ${ }^{\mathrm{TM}}$ transfection Agent (Ambion, USA). MCF7-ADR and MDA-MB-468 cells were seeded and transfected with miR-500a-3p mimic or negative control mimic at a final concentration of $15 \mathrm{nM}$. After 24 hours, the cells were reseeded in 24-well plates at a density of $2 \times 10^{5}$ per well then treated with a range of 4-OHT concentrations from 1 to $10 \mu \mathrm{M}$, and incubated for 48 hours. The WST-8 $\left(\mathrm{Enzo}^{\circledR}\right.$, USA) labeling mixture was added to each well and quantified using a scanning 96-well spectrophotometer according to the manufacturer's protocol.

\section{Caspase- 3 activation assay}

T47D and T47D/LY6K were treated with vehicle or 4-OHT and then incubated for $3 \mathrm{hr}$. T47D/LY6K cells were transfected with miR-192-5p inhibitor or negative control then treated with 4-OHT. MCF7-ADR cells were 
seeded in $100 \mathrm{~mm}$ dishes with miR-500a-3p mimic or negative control mimic. Then, 4-Hydroxytamoxifen (4-OHT) was treated at final concentration of $30 \mathrm{nM}$. After 48 hours, cells were lysed and the cell lysates were employed to measure the activity of a Caspase-3 using Caspase-3/CPP32 Colorimetric Assay Kit (Biovision, USA) according to the manufacturer's instructions.

\section{Cell apoptosis by flow cytometry analysis}

Drug-induced apoptotic cell death was analyzed using measurement of apoptotic cell by flow cytometry. Briefly, cells were treated with tamoxifen and incubated for $24 \mathrm{hr}$. Cell were collected and washed ice-cold 1 X PBS and then fixed with cold $70 \%$ ethanol overnight. Fixed cell stained with $20 \mu \mathrm{g} / \mathrm{ml}$ propidium iodide in PBS containing $100 \mu \mathrm{g} / \mathrm{ml}$ RNase A for 30 minutes and then analyzed by FACSCanto II flow cytometry (BD biosciences, USA).

\section{Analysis of patient data}

The mRNA data set for the comparison of LY6K and $\mathrm{ER} \alpha$ expression obtained from the Oncomine ${ }^{\mathrm{TM}}$ (Compendia Bioscience, Ann Arbor, MI) was used for analysis and visualization. The miRNA expression analysis in ER+ tumors after tamoxifen treatment was obtained from the NCBI GEO database (GSE 46823 [30]). The data on overall survival of breast cancer patients receiving adjuvant Tamoxifen mono-therapy was acquired from drugsurv (http://www.bioprofiling.de/GEO/DRUGSURV/index.html) using the NCBI GEO database (GSE37405 [31]).

\section{Statistical analysis}

All experiments were repeated at least three times in this study. One-tailed $t$-test was performed by GraphPad InStat (Graphpad software, La Jolla, CA, USA). Values were reported as means \pm SD. $P<0.05$ was considered significant. $(* P<0.05 ; * * P<0.01 ; * * * P<0.001$; $* * * * P<0.0001)$.

\section{ACKNOWLEDGMENTS}

This study was supported by the National Research Foundation of Korea (NRF) grant funded by the Korea government (MSIP) (2016R1A2A1A05005295, and Research fellow 2013R1A1A2059379).

\section{CONFLICTS OF INTEREST}

Authors declare no conflicts of interest.

\section{GRANT SUPPORT}

This work was supported by the National Research Foundation of Korea grant funded by the Korea government (2013R1A2A1A01011908 and Research fellow 2013R1A1A2059379).

\section{REFERENCES}

1. Nguyen PL, Taghian AG, Katz MS, Niemierko A, Abi Raad RF, Boon WL, Bellon JR, Wong JS, Smith BL, Harris JR. Breast cancer subtype approximated by estrogen receptor, progesterone receptor, and HER-2 is associated with local and distant recurrence after breast-conserving therapy. Journal of clinical oncology. 2008; 26:2373-2378.

2. Vargo-Gogola T, Rosen JM. Modelling breast cancer: one size does not fit all. Nature reviews Cancer. 2007; 7: 659-672.

3. Musgrove EA, Sutherland RL. Biological determinants of endocrine resistance in breast cancer. Nature reviews Cancer. 2009; 9:631-643.

4. Stanford JL, Szklo M, Brinton LA. Estrogen receptors and breast cancer. Epidemiologic reviews. 1986; 8:42-59.

5. Osborne CK, Schiff R. Mechanisms of endocrine resistance in breast cancer. Annual review of medicine. 2011; 62: 233-247.

6. Brakenhoff RH, Gerretsen M, Knippels EM, van Dijk M, van Essen H, Weghuis DO, Sinke RJ, Snow GB, van Dongen GA. The human E48 antigen, highly homologous to the murine Ly-6 antigen ThB, is a GPI-anchored molecule apparently involved in keratinocyte cell-cell adhesion. The Journal of cell biology. 1995; 129:1677-1689.

7. Lee JW, Lee YS, Yoo KH, Lee KH, Park K, Ahn T, Ko C, Park JH. LY-6K gene: a novel molecular marker for human breast cancer. Oncology reports. 2006; 16:1211-1214.

8. Matsuda R, Enokida H, Chiyomaru T, Kikkawa N, Sugimoto T, Kawakami K, Tatarano S, Yoshino H, Toki K, Uchida Y, Kawahara K, Nishiyama K, Seki N, et al. LY6K is a novel molecular target in bladder cancer on basis of integrate genome-wide profiling. British journal of cancer. $2011 ; 104: 376-386$.

9. Zhang B, Zhang Z, Zhang X, Gao X, Kernstine KH, Zhong L. Serological antibodies against LY6K as a diagnostic biomarker in esophageal squamous cell carcinoma. Biomarkers. 2012; 17:372-378.

10. Kong HK, Yoon S, Park JH. The regulatory mechanism of the LY6K gene expression in human breast cancer cells. The Journal of biological chemistry. 2012; 287:38889-38900.

11. Calin GA, Croce CM. MicroRNA signatures in human cancers. Nature reviews Cancer. 2006; 6:857-866.

12. Hur K. MicroRNAs: promising biomarkers for diagnosis and therapeutic targets in human colorectal cancer metastasis. BMB reports. 2015; 48:217-222.

13. Iorio MV, Ferracin M, Liu CG, Veronese A, Spizzo R, Sabbioni S, Magri E, Pedriali M, Fabbri M, Campiglio M, Menard S, Palazzo JP, Rosenberg A, et al. MicroRNA gene expression deregulation in human breast cancer. Cancer research. 2005; 65:7065-7070. 
14. Zhao JJ, Lin J, Yang H, Kong W, He L, Ma X, Coppola D, Cheng JQ. MicroRNA-221/222 negatively regulates estrogen receptor alpha and is associated with tamoxifen resistance in breast cancer. The Journal of biological chemistry. 2008; 283:31079-31086.

15. Miller TE, Ghoshal K, Ramaswamy B, Roy S, Datta J, Shapiro CL, Jacob S, Majumder S. MicroRNA-221/222 confers tamoxifen resistance in breast cancer by targeting p27Kip1. The Journal of biological chemistry. 2008; 283:29897-29903.

16. Lu Y, Roy S, Nuovo G, Ramaswamy B, Miller T, Shapiro C, Jacob ST, Majumder S. Anti-microRNA-222 (anti-miR-222) and -181B suppress growth of tamoxifenresistant xenografts in mouse by targeting TIMP3 protein and modulating mitogenic signal. The Journal of biological chemistry. 2011; 286:42292-42302.

17. Lu M, Ding K, Zhang G, Yin M, Yao G, Tian H, Lian J, Liu L, Liang M, Zhu T, Sun F. MicroRNA-320a sensitizes tamoxifen-resistant breast cancer cells to tamoxifen by targeting ARPP-19 and ERRgamma. Scientific reports. $2015 ; 5: 8735$.

18. Ward A, Balwierz A, Zhang JD, Kublbeck M, Pawitan Y, Hielscher T, Wiemann S, Sahin O. Re-expression of microRNA-375 reverses both tamoxifen resistance and accompanying EMT-like properties in breast cancer. Oncogene. 2013; 32:1173-1182.

19. Cittelly DM, Das PM, Spoelstra NS, Edgerton SM, Richer JK, Thor AD, Jones FE. Downregulation of miR342 is associated with tamoxifen resistant breast tumors. Molecular cancer. 2010; 9:317.

20. Perry RR, Kang Y, Greaves B. Effects of tamoxifen on growth and apoptosis of estrogen-dependent and -independent human breast cancer cells. Annals of surgical oncology. 1995; 2:238-245.

21. Bjornstrom L, Sjoberg M. Mechanisms of estrogen receptor signaling: convergence of genomic and nongenomic actions on target genes. Molecular endocrinology. 2005; 19:833-842.

22. Iorio MV, Croce CM. MicroRNA dysregulation in cancer: diagnostics, monitoring and therapeutics. A comprehensive review. EMBO molecular medicine. 2012; 4:143-159.
23. Choi SH, Kong HK, Park SY, Park JH. Metastatic effect of LY-6K gene in breast cancer cells. International journal of oncology. 2009; 35:601-607.

24. Rao JS. Molecular mechanisms of glioma invasiveness: the role of proteases. Nature reviews Cancer. 2003; 3:489-501.

25. Chung AC, Huang XR, Meng X, Lan HY. miR-192 mediates TGF-beta/Smad3-driven renal fibrosis. Journal of the American Society of Nephrology. 2010; 21:1317-1325.

26. Hummel R, Sie C, Watson DI, Wang T, Ansar A, Michael MZ, Van der Hoek M, Haier J, Hussey DJ. MicroRNA signatures in chemotherapy resistant esophageal cancer cell lines. World journal of gastroenterology. 2014; 20:14904-14912.

27. Giacinti L, Claudio PP, Lopez M, Giordano A. Epigenetic information and estrogen receptor alpha expression in breast cancer. The oncologist. 2006; 11:1-8.

28. Yan L, Nass SJ, Smith D, Nelson WG, Herman JG, Davidson NE. Specific inhibition of DNMT1 by antisense oligonucleotides induces re-expression of estrogen receptoralpha (ER) in ER-negative human breast cancer cell lines. Cancer biology \& therapy. 2003; 2:552-556.

29. Saxena NK, Sharma D. Epigenetic Reactivation of Estrogen Receptor: Promising Tools for Restoring Response to Endocrine Therapy. Molecular and cellular pharmacology. 2010; 2:191-202.

30. Hoppe R, Achinger-Kawecka J, Winter S, Fritz P, Lo WY, Schroth W, Brauch H. Increased expression of miR126 and miR-10a predict prolonged relapse-free time of primary oestrogen receptor-positive breast cancer following tamoxifen treatment. European journal of cancer. 2013; 49:3598-3608.

31. Lyng MB, Laenkholm AV, Sokilde R, Gravgaard KH, Litman T, Ditzel HJ. Global microRNA expression profiling of high-risk ER+ breast cancers from patients receiving adjuvant tamoxifen mono-therapy: a DBCG study. PloS one. 2012; 7:e36170. 